Correspondence

Mamta Chawla-Sarkar chawlam70@gmail.com

Received 21 March 2009

Accepted 24 August 2009

\section{Comparative evaluation of real-time PCR and conventional RT-PCR during a 2 year surveillance for influenza and respiratory syncytial virus among children with acute respiratory infections in Kolkata, India, reveals a distinct seasonality of infection}

\author{
Anurodh S. Agrawal, ${ }^{1}$ Mehuli Sarkar, ${ }^{1}$ Sekhar Chakrabarti, ${ }^{1}$ K. Rajendran, ${ }^{2}$ \\ Harpreet Kaur, ${ }^{3}$ Akhilesh C. Mishra, ${ }^{4}$ Mrinal K. Chatterjee, ${ }^{5}$ \\ Trailokya N. Naik, ${ }^{6}$ Mandeep S. Chadha ${ }^{4}$ and Mamta Chawla-Sarkar ${ }^{1}$ \\ ${ }^{1}$ Division of Virology, National Institute of Cholera and Enteric Diseases, P-33 CIT Road Scheme \\ XM, Beliaghata, Kolkata 700010, India \\ ${ }^{2}$ Division of Data Management, National Institute of Cholera and Enteric Diseases, P-33 CIT Road \\ Scheme XM, Beliaghata, Kolkata 700010, India \\ ${ }^{3}$ Indian Council of Medical Research, Ansari Nagar, New Delhi 110029, India \\ ${ }^{4}$ National Institute of Virology, 20A Ambedkar Road, Pune 411001, India \\ ${ }^{5}$ Dr B. C. Roy Memorial Hospital for Children, Narkeldanga Main Road, Kolkata 700054, India \\ ${ }^{6}$ School of Biology, National Institute of Science Education and Research, Bhubhaneshwar \\ 751005, India
}

\begin{abstract}
Acute respiratory tract infections (ARTIs) are one of the most common causes of morbidity and mortality in young children worldwide. Influenza virus and respiratory syncytial virus (RSV) are the predominant aetiological agents during seasonal epidemics, and thus rapid and sensitive molecular tests for screening for such agents and timely identification of epidemics are required. This study compared real-time quantitative PCR (qPCR) with conventional RT-PCR for parallel identification of influenza A virus (IAV) or influenza B virus (IBV) and RSV. A total of 1091 respiratory samples was examined from children with suspected ARTls between January 2007 and December 2008. Of these, 275 (25.21\%) were positive for either influenza or RSV by qPCR compared with 262 (24.01\%) positive by RT-PCR. Overall, IAV, IBV and RSV were detected in $121(11.09 \%), 59(5.41 \%)$ and 95 (8.71\%) samples, respectively. In spite of overlapping clinical symptoms, RSV and influenza virus showed distinct seasonal peaks. IAV correlated positively and RSV negatively with rainfall and temperature. No distinct seasonality was observed in IBV infections. This is, to the best of our knowledge, the first report of a systemic surveillance of respiratory viruses with seasonal correlation and prevalence rates from eastern India. This 2 year comparative analysis also confirmed the feasibility of using qPCR in developing countries, which will not only improve the scope for prevention of epidemics, but will also provide crucial epidemiological data from tropical regions.
\end{abstract}

\section{INTRODUCTION}

Acute respiratory tract infections (ARTIs) are among the most common causes of significant morbidity and mortality in young children, the elderly and immunocompromised patients, with the greatest number of deaths

Abbreviations: ARTI, acute respiratory tract infection; $\mathrm{Cl}$, confidence interval; $C_{t}$, threshold cycle; qPCR, real-time quantitative PCR; RSV, respiratory syncytial virus; $\mathrm{TCID}_{50}, 50 \%$ tissue culture infectious dose. occurring in developing countries (Williams et al., 2002). One-quarter (2.5 million) of the total deaths among children less than 5 years of age occurs in India, and approximately $20 \%$ of these are due to ARTIs (Reddaiah \& Kapoor, 1988; Rao, 2003). In addition to bacterial infections, influenza virus and respiratory syncytial virus (RSV) have been identified as the predominant aetiological agents for lower respiratory tract infections (Stockton et al., 1998; Thompson et al., 2004; Ieven, 2007). These viruses 
result in the rapid onset of symptoms, which include fever $\left(\geqslant 38.8^{\circ} \mathrm{C}\right)$, headache, cough, chill and sore throat. In children with chronic abnormalities of pulmonary function, infections with influenza virus or RSV have been shown to aggravate asthma (Wang \& Forsyth, 1998). As treatment needs to be initiated within $24-48 \mathrm{~h}$ of infection to be successful, rapid diagnosis of viral pathogens during regular surveillance studies is of the utmost importance. Moreover, timely identification of epidemics, their seasonality and the burden of strain subtypes in the community are important for proper clinical interventions (Adcock et al., 1997; Van Elden et al., 2002; Ruest et al., 2003; Liao et al., 2009).

Diagnostic methods currently used for the detection of respiratory infections in clinical laboratories include rapid antigen tests, virus culture, enzyme immunoassays, immunofluorescence and conventional RT-PCR assays (Falsey et al., 2002; Ruest et al., 2003). Virus culture is considered the gold standard and also provides reference strains for vaccine development, genetic characterization and in vivo studies to understand pathogenesis; however, it can take 712 days to obtain a positive culture (Van Elden et al., 2002). In the last decade, molecular diagnostics such as RTPCR and real-time quantitative PCR (qPCR) have gained importance due to their higher sensitivity. These tests can also detect more than one pathogen in a single reaction by simultaneously using multiple probes (multiplex PCR) to reduce time and cost (Stockton et al., 1998; Fredricks \& Relman, 1999; Van Elden et al., 2001; Boivin et al., 2004).

The recent outbreaks of avian influenza virus (H5N1) and the novel H1N1 (swine flu) worldwide serve as a grim reminder that another influenza pandemic appears to be on the horizon. Thus, continuous surveillance for respiratory viruses with a focus on influenza virus in developing countries is the key for controlling pandemics. Few virological or epidemiological data are available regarding respiratory viruses in eastern and south-eastern Asian countries except for a few reports from Japan, Thailand, Taiwan, Singapore and Hong Kong (Viboud et al., 2006; Park \& Glass, 2007; Simmerman \& Uyeki, 2008). India is a large country, and close to $20 \%$ of its population is below 5 years of age. It has a tropical climate with distinct seasonal variations from north to south. In India, the effects of influenza pandemics in 1889, 1918 (H1N1), 1957 (H2N2) and 1968 (H3N2) (Rao \& Banerjee, 1993) were also felt (Rao \& Banerjee, 1993; Rao, 2003). In 1968, Hong Kong flu (H3N2) epidemics were reported from Maharashtra, Andhra Pradesh, Kolkata, Nepal and other regions. Unfortunately, little epidemiological or virological information on respiratory viruses has been reported from India in the last decade, as respiratory diseases have not been taken seriously compared with other infectious diseases, such as AIDS, cholera and malaria. Due to multiple outbreaks of the highly pathogenic $\mathrm{H} 5 \mathrm{~N} 1$ virus in poultry in India during 2006-2009, we started a surveillance programme for circulating respiratory viruses among children under 5 years of age in Kolkata, a metropolitan city in West Bengal,
India $\left(88^{\circ} 18^{\prime} \mathrm{E}, 22^{\circ} 39^{\prime} \mathrm{N}\right)$ to determine the frequency of influenza A virus (IAV), influenza B virus (IBV) and RSV infection. The frequency of influenza virus and RSV positivity was correlated with meteorological factors to determine the seasonality of infections in eastern India. In this study, two multiplex qPCR assays were used for the detection of IAV and IBV, and RSV and RNase P (a positive internal control), respectively. The assay was also compared with conventional RT-PCR and virus culture to assess its potential application in routine surveillance and diagnosis.

\section{METHODS}

Sampling site and study population. Nasal and/or throat swabs were collected from 1091 children $\leqslant 5$ years old exhibiting fever and two or more symptoms of ARTI (cold/cough, sore throat, myalagia, aches) from the outdoor patient ward of the Dr B. C. Roy Memorial Hospital for Children, Kolkata, India, over 2 years (January 2007December 2008). This hospital is one of the largest children's hospitals in eastern India, treating patients from rural and urban areas located in and around (up to $80 \mathrm{~km}$ ) Kolkata. No hospitalized patients were included in the study to rule out nosocomial infections. Specimens were transported in virus transport medium (Hanks' balanced salt solution with $200 \mathrm{U}$ penicillin $\mathrm{ml}^{-1} / 200 \mu \mathrm{g}$ streptomycin $\mathrm{ml}^{-1}$ and $2 \%$ BSA). Sample of $200 \mu \mathrm{l}$ were processed immediately on receipt at the laboratory for viral RNA isolation.

The study was approved by the Institutional Ethical Committee and informed consent was taken from the guardians of patients before collection of samples.

Extraction of viral RNA. RNA was extracted from the clinical samples using an RNeasy Mini kit (Qiagen) following the manufacturer's instructions. The RNA was stored in aliquots at $-80{ }^{\circ} \mathrm{C}$ until use.

Primers and probe design. Two one-step multiplex qPCR assays were standardized. For the first multiplex assay, primers were designed from conserved regions of the matrix (M) genes of IAV and IBV. The conserved $M$ gene primers (IAV) were checked for sequence identity by BLAST analysis with $>100$ published sequences of influenza virus subtypes (H1N1, H3N2, H5N1 and swine H1N1) reported from human samples. The IAV, IBV and RNase $\mathrm{P}$ (positive internal control) primers and probe sequences used in the study were provided by the Centers for Disease Control and Prevention (available on request from S. Lindstrom, Centers for Disease Control and Prevention, USA). The second multiplex assay was specific to the polymerase (L) gene of RSV and RNase P (Templeton et al., 2004). Three different reporter dyes, namely FAM (6-carboxyfluorescein) (IAV and RNase P), VIC (IBV) and HEX (RSV), were used in the study, with the quencher dye BHQ-1.

qPCR. TaqMan qPCR was performed using a one-step RT-PCR kit (Invitrogen) with a $25 \mu \mathrm{l}$ reaction mixture containing $5 \mu \mathrm{l}$ extracted RNA, $12.5 \mu \mathrm{l} 2 \times$ reaction mix with ROX, $0.5 \mu \mathrm{M}$ each primer and probe, $20 \mathrm{U}$ RNase OUT and $0.5 \mu \mathrm{l}$ Superscript III RT/Platinum Taq mix following the kit protocol, on an ABI Prism 7500 sequence detection system. The PCR cycling conditions consisted of an initial reverse transcriptase step at $50{ }^{\circ} \mathrm{C}$ for $15 \mathrm{~min}$, followed by a $2 \mathrm{~min}$ hold at $95{ }^{\circ} \mathrm{C}$, and then 40 cycles of $15 \mathrm{~s}$ at $95{ }^{\circ} \mathrm{C}$ and $30 \mathrm{~s}$ at $60{ }^{\circ} \mathrm{C}$. To avoid cross-contamination, single-use aliquots were prepared for all reagents including primers, probes, buffers and enzymes. ROX was 
used as a passive reference dye to normalize the fluorescent fluctuations caused by changes in concentration or volume of sample.

Conventional RT-PCR. All clinical samples were screened in parallel by a conventional RT-PCR assay to assess the specificity and sensitivity of the qPCR assay. Multiplex RT-PCR was carried out with a primer pair for the M gene (IAV and IBV) (Donofrio et al., 1992) and N gene (RSV) (Cane \& Pringle, 1991) targeting different regions compared with the qPCR assay. The PCR products were run in a $2 \%$ agarose gel to separate the fragments of $212 \mathrm{bp}$ (IAV), $362 \mathrm{bp}$ (IBV) and $279 \mathrm{bp}$ (RSV).

Statistical analysis. Statistical analysis was carried out using SPSS 11.0.1 software (LEAD Technologies). All $P$ values were two-tailed and $P \leqslant 0.05$ was considered significant.

\section{RESULTS AND DISCUSSION}

In recent years, many single or multiplex RT-PCR protocols for the simultaneous detection of multiple respiratory viruses have been reported (Syrmis et al., 2004; Simmerman et al., 2006). Due to the high costs of instruments and reagents for qPCR, conventional RT-PCRs and virus culture have mostly been used in surveillance studies in south-east Asia (Ieven, 2007; Simmerman \& Uyeki, 2008). However, early diagnosis by rapid qPCR may result in indirect cost benefits such as decreased use of antibiotics, appropriate use of antiviral drugs and reduced hospitalization rates (Adcock et al., 1997; Woo et al., 1997).

In this study, we used two multiplex qPCR assays, using two fluorophores, for IAV, IBV and RSV for routine surveillance for these respiratory viruses. Both assays were performed on the same sample plate with the same temperature profile. The majority of samples screened were nasal or throat swabs, and no inhibitory effects on PCR were observed (Boivin et al., 2004).

\section{Standardization of sensitivity and specificity for qPCR}

The multiplex qPCR assay was first evaluated for crossreactivity between viruses by using RSV RNA with influenza virus-specific primers and vice versa. In addition, clinical samples negative for influenza virus or RSV, but positive for metapneumovirus or rhinovirus were tested to check the primers for cross-reactivity. No non-specific cross-amplification was observed. To address the issues of false-negative and false-positive results, an internal positive control gene (RNase P), positive control RNAs for IAV, IBV and RSV, and a negative (throat swab) control were included in all reactions. All samples were tested twice independently. The frequency of contamination was less than $0.2 \%(1: 500)$, as indicated by a false-positive signal in negative controls.

In order to determine the sensitivity of the assay, RNA was isolated from tenfold dilutions of a $50 \%$ tissue culture infectious dose $\left(\mathrm{TCID}_{50}\right)$-titrated stock of IAV, IBV or RSV and analysed by qPCR in triplicate. The minimal amount of detectable RNA corresponded to approximately 0.1 $\mathrm{TCID}_{50}$ for IAV and IBV, and approximately $0.01 \mathrm{TCID}_{50}$ for RSV. The threshold cycle $\left(C_{t}\right)$ values of the multiplex qPCR were within \pm 2 cycles of the monospecific assay. The IAV primer detected the positive-control RNA of $\mathrm{H} 1 \mathrm{~N} 1, \mathrm{H} 3 \mathrm{~N} 2$ and $\mathrm{H} 5 \mathrm{~N} 1$ viruses, indicating its sensitivity to detect common IAV subtypes. To confirm the specificity of the TaqMan primers and probe, nucleotide sequencing of randomly selected positive (IAV, IBV or RSV) and negative samples ( $n=10$ of each) was carried out. There was $100 \%$ corroboration of the sequencing results with the qPCR results. Two samples showed a mixed infection with IAV and IBV, although the mean $C_{\mathrm{t}}$ value of IBV was $\geqslant 34.0$ compared with 23.6 for IAV. To cross-check whether this was an artefact of multiplexing, a monospecific PCR with IBV primers was performed. The monospecific qPCR also gave a positive signal $\left(C_{\mathrm{t}} \geqslant 33.2\right)$ confirming the presence of low levels of IBV in the samples. The amplified IAV and IBV products were confirmed by sequencing. Mixed infection was not an artefact of the PCR reagents, as three independent experiments using fresh aliquots of reagents confirmed the results. However, whether the patient had dual infection or the clinical sample had become contaminated during collection in hospital could not be ascertained.

\section{Frequency of influenza virus- and RSV-mediated ARTIs in children}

All samples were screened by multiplex qPCR. Of 1091 samples tested, 275 (25.21\%) were positive for respiratory viruses (IAV, IBV and RSV). Overall, IAV, IBV and RSV were identified in a total of $121(11.09 \%), 59(5.41 \%)$ and $95(8.71 \%)$ samples, respectively. The IAV frequency increased during May-September, whereas RSV infection was predominant during November-February in both years. IBV infections preceded or followed the IAV and RSV season with a 5-10\% frequency during March-April and September-October (Fig. 1).

As the IAV primer (specific for the M gene) could not differentiate between subtypes, positive samples required another round of PCR for subtyping. Of $66 \mathrm{IAV}$-positive samples in 2007, 48 were subtyped as $\mathrm{H} 1 \mathrm{~N} 1$ and 18 as H3N2, whereas in 2008, all $55 \mathrm{IAV}$-positive samples were H3N2 (data not included). Instead of screening all samples by subtype-specific assays, only IAV-positive samples (10$12 \%)$ needed to be subjected to another multiplex PCR $(\mathrm{H} 1$ and $\mathrm{H} 3)$, resulting in a reduction in costs and potential cross-contamination. Another advantage is that new subtypes can be predicted by our diagnostic strategy if a sample shows IAV positivity but is negative with $\mathrm{H} 1$ - and $\mathrm{H} 3$-specific primers.

Of the $180(121 \mathrm{IAV}+59 \mathrm{IBV})$ positive samples, only 89 $(65+24)$ were positive by virus culture. RSV culture was not carried out during the study period. Thus, compared with QPCR, the sensitivity and specificity of virus culture was 49.5 and $100 \%$, respectively (Table 1 ). A range of 


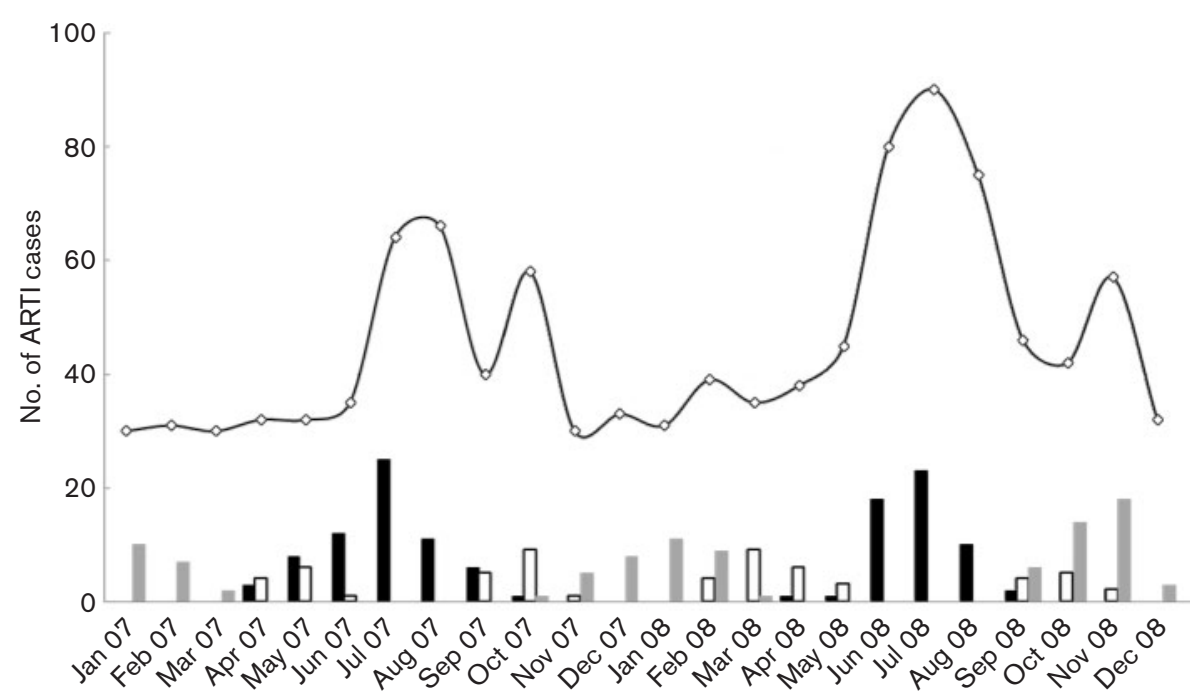

Fig. 1. Frequency of IAV, IBV and RSV in children ( $\leqslant 5$ years) reporting with ARTIs. All clinical samples were tested in triplicate by qPCR $(P<0.05)$. The number of suspected influenza-like cases and the number of virus-positive samples is shown for each month over a 2 year period (January 2007-December 2008). Black bars, IAV; white bars, IBV; grey bars, RSV; $\diamond$, samples collected.

different studies have reported a lower sensitivity for virus isolation, as influenza virus is sensitive to temperature and $\mathrm{pH}$ changes, as well as cell culture conditions (Van Elden et al., 2002; Liao et al., 2009).

\section{Comparison of qPCR with a standard RT-PCR assay}

Conventional multiplex RT-PCR was carried out in parallel to retest the specimens for independent confirmation of the results and evaluation of the multiplex qPCR assay. A total of $262(24.01 \%)$ samples were found to be positive compared with 275 by qPCR, indicating $95.2 \%$ sensitivity. The influenza virus samples that were positive by qPCR but were culture negative were also confirmed as positive by the RT-PCR method. However, RT-PCR detected only IAV in the two mixed infections detected by qPCR. In general, RT-PCR-negative samples $(n=13)$ had a higher mean $C_{\mathrm{t}}$

Table 1. Comparison of positive samples obtained by qPCR, conventional RT-PCR and virus culture during the 2 year study period $(n=1091)$

\begin{tabular}{|lccc|}
\hline Test & qPCR & $\begin{array}{c}\text { Conventional } \\
\text { RT-PCR }\end{array}$ & $\begin{array}{c}\text { Virus } \\
\text { culture }\end{array}$ \\
\hline Influenza A $(n)$ & 121 & 119 & 65 \\
Influenza B $(n)$ & 59 & 54 & 24 \\
RSV $(n)$ & 95 & 89 & ND \\
Total positive $(n)$ & 275 & 262 & - \\
Overall sensitivity $(\%)$ & $\geqslant 98$ & $\geqslant 95$ & $\geqslant 49.5$ \\
\hline
\end{tabular}

ND, Not determined. value of 30.7 (range 27.6-37.4, $P \leqslant 0.05$ ) in $\mathrm{qPCR}$ compared with 262 samples positive for both RT-PCR and TaqMan qPCR, with a mean $C_{\mathrm{t}}$ value of 24.24 (range 20.2-30.1). Thus, a lower viral load in samples was associated with false negatives in conventional RT-PCR (van Elden et al., 2002; Liao et al., 2009). In addition to its higher sensitivity, the main advantage of TaqMan qPCR over conventional RT-PCR detection is that qPCR uses virus-specific probes in the middle of the amplicon to specifically detect the product for each virus, which gives confidence in its specificity. The sensitivity of qPCR was $98.8 \%$ [95\% confidence interval (CI) 98.2-100\%] for IAV, $97.5 \%$ (95\% CI $95.8-100 \%$ ) for IBV and $98 \%$ (95\% CI 97-100\%) for RSV compared with conventional RT-PCR or virus culture.

\section{Correlation of virus infection with age}

The positive cases represented a mixed population encompassing patients from rural as well as urban settings (including slums) from in and around Kolkata city. Most of the cases were from lower-income groups (suggestive of malnutrition) and from areas with poor sanitation, facilitating the spread of respiratory infections in the community. We observed an increased prevalence of RSV in the $0-1.0(13.9 \%)$ and $1.0-2.0(12.1 \%)$ years age groups compared with only $3.8 \%$ positivity among $2-5$-year-old children. This is consistent with previous studies where $>80 \%$ of the RSV-positive samples were observed in 1-24-month-old children (Liao et al., 2009). Similar to the reports from Thailand and Taiwan (Lin et al., 2004; Simmerman et al., 2006), influenza virus $(\mathrm{A}+\mathrm{B})$ was predominant in the 1.0-2.0 and 2.0-5.0 years age groups 
Table 2. Prevalence of influenza virus and RSV infection in different age groups among children $\leqslant 5$ years $(n=1091)$

Statistical analysis was carried out using a $\chi^{2}$ test.

\begin{tabular}{|lcccc|}
\hline Virus & \multicolumn{3}{c}{ Age group } & \multirow{2}{*}{ Significance } \\
\cline { 2 - 4 } & $\begin{array}{c}\mathbf{0 - 1} \text { years } \\
(\boldsymbol{n}=\mathbf{2 1 5})\end{array}$ & $\begin{array}{c}\mathbf{1 - 2} \text { years } \\
(\boldsymbol{n}=\mathbf{3 8 2})\end{array}$ & $\begin{array}{c}\mathbf{2 - 5} \text { years } \\
(\boldsymbol{n}=\mathbf{4 9 4})\end{array}$ & \\
\hline Influenza virus & $10.2 \% \%^{*}$ & $19.6 \%$ & $17.2 \%$ & $P \leqslant 0.01$ \\
RSV & $13.9 \%$ & $12.1 \%$ & $3.8 \% *^{*}$ & $P \leqslant 0.01$ \\
\hline
\end{tabular}

*Significantly lower prevalence.

(19.6\% and $17.2 \%$ ) in Kolkata (Table 2). Thus, vaccination for seasonal influenza in these settings among children in the 1-5 years age group would be expected to reduce the disease burden in communities.

\section{Influenza and RSV infection correlates with distinct meteorological conditions}

Although RSV and influenza virus (A or B) could not be differentiated by clinical symptoms, during the 24-month study their incidence correlated with meteorological data obtained from the Meteorological Department, Kolkata, Government of India. The number of samples positive for IAV, IBV and RSV per month was plotted against mean monthly maximum and minimum temperatures, relative humidity and rainfall (Fig. 2). The increase in RSV cases correlated negatively with temperature $\left(r^{2}=0.806\right.$,
$P \leqslant 0.01)$ and rainfall $\left(r^{2}=0.37, P \leqslant 0.05\right)$, with high positivity (25-40\%) during the cool, dry months (December-February). However, in October-November 2008, there was a mild epidemic of RSV in the state of West Bengal, which did not correlate with a decrease in temperature but correlated with a drop in relative humidity and rainfall (Fig. 2).

IBV infection did not correlate with either temperature or rainfall (Fig. 2, Table 3). A direct correlation of IAV activity with rainfall $\left(r^{2}=0.811, P \leqslant 0.01\right)$, relative humidity $\left(r^{2}=0.499, P \leqslant 0.05\right)$ and temperature $\left(r^{2}=0.366, P \leqslant 0.01\right)$ was observed during both years. There was negligible IAV activity (0-2\%) during the cool, dry season (NovemberFebruary). This is comparable to data from tropical regions such as Pune city in India (Rao \& Banerjee, 1993), Dakar in Senegal (Dosseh et al., 2000), north-eastern Brazil (Alonso et al., 2007) and Thailand (Simmerman \& Uyeki, 2008), where influenza virus incidence peaks are observed during the rainy season. By contrast, increased influenza virus activity is observed during winter (December-March) in Taiwan (Lin et al., 2004; Park \& Glass, 2007), Vietnam (Nguyen et al., 2007) and Singapore (Chew et al., 1998; Chow et al., 2006), coinciding with annual epidemics of temperate regions, but there is another moderate peak in July and August coinciding with the rains (Viboud et al., 2006).

Similar to Brazil (Alonso et al., 2007), increased influenza activity was reported during the winter in northern India (December-February, mean temperature $14-20{ }^{\circ} \mathrm{C}$, relative humidity $30-45 \%$ ), but during the hot and wet season in

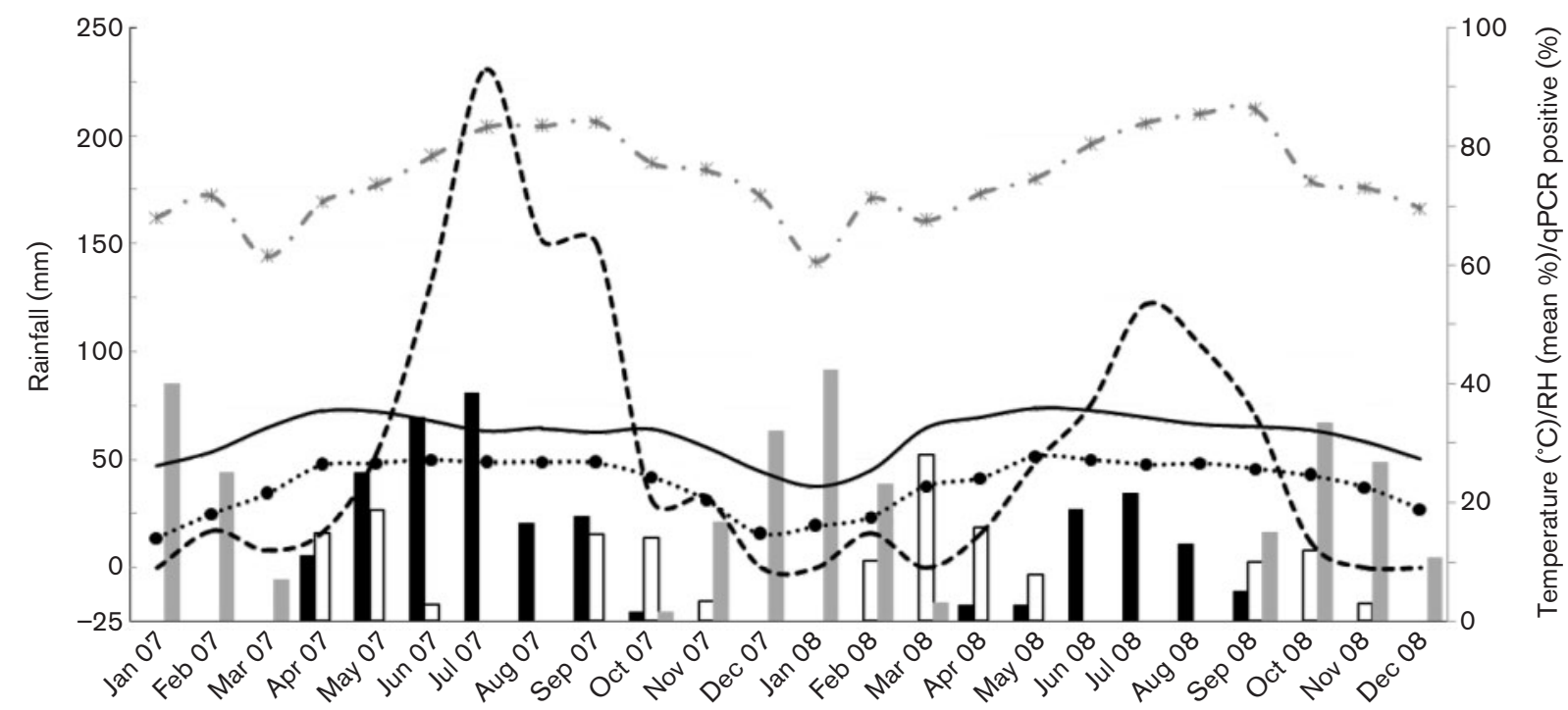

Fig. 2. Correlation of meteorological variations with prevalence of IAV, IBV and RSV (percentage of qPCR-positive samples) during 2007-2008 in Kolkata. IAV correlated positively with rainfall and temperature $\left(r^{2}=0.811\right.$ and $r^{2}=0.366$, respectively; $P \leqslant 0.01)$, but RSV correlated negatively with temperature $\left(r^{2}=0.806, P \leqslant 0.01\right)$. Black bars, IAV (\%); white bars, IBV (\%); grey bars, RSV (\%); dashed line, rainfall $(\mathrm{mm})$; solid line, temperature maximum $\left({ }^{\circ} \mathrm{C}\right) ; \boldsymbol{\bullet}$, temperature minimum $\left({ }^{\circ} \mathrm{C}\right) ; \mathrm{X}$, relative humidity $(\mathrm{RH})($ mean \%). 
Table 3. Correlation between meteorological variables and the number of influenza virus-positive and RSV-positive samples obtained during the study

\begin{tabular}{|c|c|c|c|c|c|c|c|}
\hline Variable & $r$ & $P$ value ${ }^{\star}$ & $r$ & $P$ value $^{*}$ & $r$ & $P$ value ${ }^{\star}$ & $\begin{array}{l}\text { Degrees of } \\
\text { freedom }\end{array}$ \\
\hline Relative humidity & 0.707 & 0.010 & -0.173 & 0.591 & -0.554 & 0.062 & 10 \\
\hline Maximum temperature & 0.605 & 0.037 & 0.508 & 0.091 & -0.925 & 0.000 & 10 \\
\hline Minimum temperature & 0.723 & 0.008 & 0.336 & 0.286 & -0.898 & 0.000 & 10 \\
\hline
\end{tabular}

$r$, Correlation coefficient.

${ }^{\star} P<0.05$ was considered significant.

eastern or western India, as in Kolkata or Pune (Rao \& Banerjee, 1993; Rao, 2003). Unlike temperate regions where increased activity of influenza virus during winters has been correlated with low relative humidity and low temperature, in tropical countries seasonality is less pronounced. More than one period of virus activity has been reported in tropical areas suggesting complex mechanisms underlying seasonality (Shek \& Lee, 2003; Viboud et al., 2006; Brankston et al., 2007). Some authors have suggested that climatic factors such as relative humidity, absolute humidity, low temperature and UV radiation may alter virus survival and transmission efficiency, and behavioural changes, such as human crowding, may also play a role (Tellier, 2006; Brankston et al., 2007; Lowen et al., 2008; Weber \& Stilianakis, 2008; Shaman \& Kohn, 2009), thus affecting virus seasonality. Another hypothesis is that, in the tropics, contact transmission predominates, whilst in temperate regions, airborne transmission by droplets is the predominant factor responsible for differences in incidence peaks (Lowen et al., 2008); however, the explanation for the seasonality of influenza virus as well as other respiratory virus infections in the tropics remains elusive. It seems that the combination of environmental and population determinants together may affect the seasonality of virus infections.

Further long-term epidemiological studies are warranted to fully understand the seasonal triggers of influenza globally. Moreover, the tropical regions with year-round virus activity could be an important reservoir for human influenza virus, ensuring global persistence of the disease and a potential source of new virus variants. This is believed to be the first report providing seasonal correlation and a prevalence rate for respiratory viruses in children from eastern India. Comparative analysis of RTPCR, qPCR and virus culture (for influenza virus) further confirmed the sensitivity, specificity and rapidity of qPCR. Thus, the future use of qPCR in Asia as a first-line test for monitoring influenza virus and RSV in hospital and community settings will result in more rapid detection of epidemics, effective clinical interventions and reduced morbidity.

\section{ACKNOWLEDGEMENTS}

This study was partly supported by financial assistance from the Indian Council of Medical Research (ICMR), New Delhi, India, and the Centers for Disease Control and Prevention, USA. We acknowledge Dr Sanjib Bhattacharya, Chief Molecular Scientist, Milwaukee, USA, for training in the technique of $\mathrm{qPCR}$, and $\mathrm{Dr}$ Byomkesh Manna, National Institute of Cholera and Enteric Diseases, India, for statistical analysis. Ms Swati Ghosh provided technical assistance during clinical sample collection and maintenance of cell cultures. A.S.A. and M.S. are supported by Senior Research Fellowships from the Indian Council of Medical Research, Government of India.

\section{REFERENCES}

Adcock, P. M., Stout, G. G., Hauck, M. A. \& Marshall, G. S. (1997). Effect of rapid viral diagnosis on the management of children hospitalized with lower respiratory tract infection. Pediatr Infect Dis J 16, 842-846.

Alonso, W. J., Viboud, C., Simonsen, L., Hirano, E. W., Daufenbach, L. Z. \& Miller, M. A. (2007). Seasonality of influenza in Brazil: a travelling wave from the Amazon to the subtropics. Am J Epidemiol 165, 1434-1442.

Boivin, G., Cote, S., Dery, P., De Serres, G. \& Bergeron, M. G. (2004). Multiplex real-time PCR assay for detection of influenza and human respiratory syncytial viruses. J Clin Microbiol 42, 45-51.

Brankston, G., Gitterman, L., Hirji, Z., Lemieux, C. \& Gardam, M. (2007). Transmission of influenza A in human beings. Lancet Infect Dis 7, 257-265.

Cane, P. A. \& Pringle, C. R. (1991). Respiratory syncytial virus heterogeneity during an epidemic analysis by limited nucleotide sequencing (SH gene) and restriction mapping ( $\mathrm{N}$ gene). J Gen Virol 72, 349-357.

Chew, F. T., Doraisingham, S., Ling, A., Kumarasinghe, G. \& Lee, B. W. (1998). Seasonal trends of viral respiratory tract infections in the tropics. Epidemiol Infect 121, 121-128.

Chow, A., Ma, S., Ling, A. E. \& Chew, S. K. (2006). Influenzaassociated deaths in tropical Singapore. Emerg Infect Dis 12, 114-121.

Donofrio, J. C., Coonrod, J. D., Davidson, J. N. \& Betts, R. F. (1992). Detection of influenza A and B in respiratory secretions with the polymerase chain reaction. PCR Methods Appl 1, 263-268.

Dosseh, A., Ndiaye, K., Spiegel, A., Sagna, M. \& Mathiot, C. (2000). Epidemiological and virological influenza survey in Dakar, Senegal: 1996-1998. Am J Trop Med Hyg 62, 639-643. 
Falsey, A. R., Formica, M. A. \& Walsh, E. E. (2002). Diagnosis of respiratory syncytial virus infection: comparison of reverse transcription-PCR to viral culture and serology in adults with respiratory illness. J Clin Microbiol 40, 817-820.

Fredricks, D. N. \& Relman, D. A. (1999). Application of polymerase chain reaction to the diagnosis of infectious diseases. Clin Infect Dis 29, 475-486.

leven, M. (2007). Currently used nucleic acid amplification tests for the detection of viruses and atypicals in acute respiratory infections. J Clin Virol 40, 259-276.

Liao, R. S., Tomalty, L. L., Majury, A. \& Zoutman, D. E. (2009). Comparison of viral isolation and multiplex real-time reverse transcriptase-PCR for confirmation of respiratory syncytial virus and influenza virus detection by antigen immunoassays. J Clin Microbiol 47, 527-532.

Lin, T. Y., Huang, Y. C., Ning, H. C. \& Tsao, K. C. (2004). Surveillance of respiratory viral infections among pediatric outpatients in northern Taiwan. J Clin Virol 30, 81-85.

Lowen, A. C., Steel, J., Mubareka, S. \& Palese, P. (2008). High temperature $\left(30^{\circ} \mathrm{C}\right)$ blocks aerosol but not contact transmission of influenza virus. J Virol 82, 5650-5652.

Nguyen, H. L. K., Saito, R., Ngiem, H. K., Nishikawa, M., Shobugawa, Y., Nguyen, D. C., Hoang, L. T., Huynh, L. P. \& Suzuki, H. (2007). Epidemiology of influenza in Hanoi, Vietnam, from 2001 to 2003. J Infect 55, 58-63.

Park, A. W. \& Glass, K. (2007). Dynamic patterns of avian and human influenza in east and southeast Asia. Lancet Infect Dis 7, 543548.

Rao, B. L. (2003). Epidemiology and control of influenza. Natl Med J India 16, 143-149.

Rao, B. L. \& Banerjee, K. (1993). Influenza surveillance in Pune, India, 1978-90. Bull World Health Organ 71, 177-181.

Reddaiah, V. P. \& Kapoor, S. K. (1988). Acute respiratory infections in rural underfives. Indian J Pediatr 55, 424-426.

Ruest, A., Michaud, S., Deslandes, S. \& Frost, E. H. (2003). Comparison of the Directigen flu A + B test, the QuickVue influenza test, and clinical case definition to viral culture and reverse transcription-PCR for rapid diagnosis of influenza virus infection. J Clin Microbiol 41, 3487-3493.

Shaman, J. \& Kohn, M. (2009). Absolute humidity modulates influenza survival, transmission, and seasonality. Proc Natl Acad Sci U S A 106, 3243-3248.

Shek, L. P. \& Lee, B. W. (2003). Epidemiology and seasonality of respiratory tract virus infections in the tropics. Paediatr Respir Rev 4, $105-111$.
Simmerman, J. M. \& Uyeki, T. M. (2008). The burden of influenza in East and South-East Asia: a review of the English language literature. Influenza Other Respi Viruses 2, 81-92.

Simmerman, J. M., Lertiendumrong, J., Dowell, S. F., Uyeki, T., Olsen, S. J., Chittaganpitch, M., Chunsutthiwat, S. \& Tangcharoensathien, V. (2006). The cost of influenza in Thailand. Vaccine 24, 4417-4426.

Stockton, J., Ellis, J. S., Saville, M., Clewley, J. P. \& Zambon, M. C. (1998). Multiplex PCR for typing and subtyping influenza and respiratory syncytial viruses. J Clin Microbiol 36, 2990-2995.

Syrmis, M. W., Whiley, D. M., Thomas, M., Mackay, I. M., Williamson, J., Siebert, D. J., Nissen, M. D. \& Sloots, T. P. (2004). A sensitive, specific and cost-effective multiplex reverse transcriptase PCR assay for the detection of seven respiratory viruses in respiratory samples. J Mol Diagn 6, 125-131.

Tellier, R. (2006). Review of aerosol transmission of influenza A virus. Emerg Infect Dis 12, 1657-1662.

Templeton, K. E., Scheltinga, S. A., Beersma, M. F. C., Kroes, A. C. M. \& Class, E. C. J. (2004). Rapid and sensitive method using multiplex real-time PCR for diagnosis of infections by influenza A and influenza $B$ viruses, respiratory syncytial virus, and parainfluenza viruses $1,2,3$, and 4. J Clin Microbiol 42, 1564-1569.

Thompson, W. W., Shay, D. K., Weintraub, E., Brammer, L., Bridges, C. B., Cox, N. J. \& Fukuda, K. (2004). Influenza-associated hospitalizations in the United States. JAMA 292, 1333-1340.

Van Elden, L. J., Nijhuis, M., Schipper, P., Schuurman, R. \& Van Loon, A. M. (2001). Simultaneous detection of influenza viruses A and B using real-time quantitative PCR. J Clin Microbiol 39, 196-200.

Van Elden, L. J., Van Kraaij, N. M., Hendriksen, K. A., Dekker, A. W., Rozenberg-Arska, M. \& Van Loon, A. M. (2002). Polymerase chain reaction is more sensitive than viral culture and antigen testing for the detection of respiratory viruses in adults with hematological cancer and pneumonia. Clin Infect Dis 34, 177-183.

Viboud, C., Alonso, W. J. \& Simonsen, L. (2006). Influenza in tropical regions. PLoS Med 3, e89.

Wang, S. Z. \& Forsyth, K. D. (1998). Asthma and respiratory syncytial virus infection in infancy: is there a link? Clin Exp Allergy 28, 927-935.

Weber, T. P. \& Stilianakis, N. I. (2008). Inactivation of influenza A viruses in the environment and modes of transmission: a critical review. J Infect 57, 361-373.

Williams, B. G., Gouws, E., Boschi-Pinto, C., Bryce, J. \& Dye, C. (2002). Estimates of world-wide distribution of child deaths from acute respiratory infections. Lancet Infect Dis 2, 25-32.

Woo, P. C., Chiu, S. S., Seto, W. H. \& Peiris, M. (1997). Costeffectiveness of rapid diagnosis of viral respiratory tract infections in pediatric patients. J Clin Microbiol 35, 1579-1581. 